\title{
Alterations in the expression of atrial calpains in electrical and structural remodeling during aging and atrial fibrillation
}

\author{
GUO-JUN XU ${ }^{1}$, TIAN-YI GAN ${ }^{1}$, BAO-PENG TANG ${ }^{1}$, ZU-HENG CHEN $^{1}$, AILIMAN MAHEMUTI ${ }^{1}$, \\ TAO JIANG ${ }^{2}$, JIAN-GUO SONG ${ }^{3}$, XIA GUO $^{4}$, YAO-DONG LI ${ }^{1}$, \\ XIAN-HUI ZHOU ${ }^{1}$, YU ZHANG ${ }^{3}$ and JIN-XIN LI ${ }^{4}$ \\ Departments of ${ }^{1}$ Cardiology and ${ }^{2}$ Animal Experiment; ${ }^{3}$ Laboratory of Electrophysiology, First Affiliated Hospital, \\ Xinjiang Medical University; ${ }^{4}$ Department of Molecular Biology, Xinjiang Medical University, \\ Urumqi, Xinjiang 830011, P.R. China
}

Received February 19, 2013; Accepted August 16, 2013

DOI: $10.3892 / \mathrm{mmr} .2013 .1684$

\begin{abstract}
The aim of this study was to investigate the correlation between the change in the expression of atrial calpains and electrical, molecular and structural remodeling during aging and atrial fibrillation (AF). Adult and aged canines in sinus rhythm (SR) and with persistent AF (induced by rapid atrial pacing) were investigated. A whole-cell patch clamp was used to measure the L-type $\mathrm{Ca}^{2+}$ current $\left(\mathrm{I}_{\mathrm{Ca-L}}\right)$ in cells in the left atrium. The mRNA and protein expression of the L-type calcium channel alc subunit $\left(\mathrm{LVDCC}_{\mathrm{alc}}\right)$ and calpains were measured by quantitative (q)PCR and western blot analysis. Histopathological and ultrastructural changes were analyzed via light and electron microscopy. The quantity of apoptotic myocytes was determined by a terminal deoxynucleotidyl-transferase-mediated dUTP nick end labeling (TUNEL) assay. In SR groups, atrial cells of the aged canines exhibited a longer action potential (AP) duration to $90 \%$ repolarization $\left(\mathrm{APD}_{90}\right)$, lower $\mathrm{AP}$ plateau potential and peak $\mathrm{I}_{\mathrm{Ca-L}}$ current densities $(\mathrm{P}<0.05)$. In the adult and aged groups, AF led to a higher maximum diastolic potential, an increase in AP amplitude and decreases in $\mathrm{APD}_{90}$, AP plateau potential and peak $\mathrm{I}_{\mathrm{Ca}-\mathrm{L}}$ densities $(\mathrm{P}<0.05)$. Compared with the control group, the mRNA and protein expression levels of $\mathrm{LVDCC}_{\mathrm{alc}}$ were decreased in the aged groups; however, the mRNA and protein expression of calpain 1 was increased in the adult and the aged groups with AF $(\mathrm{P}<0.05)$. Samples of atrial tissue exhibited abnormal histopathological and ultrastructural changes, such as accelerated fibrosis and apoptosis with aging and in AF. Age-related alterations in atrial tissues were attributed to the increased expression of calpain 1. The general
\end{abstract}

Correspondence to: Professor Bao-Peng Tang, Department of Cardiology, First Affiliated Hospital, Xinjiang Medical University, 137 Liyushan South Road, Urumqi, Xinjiang 830011, P.R. China E-mail: baopengtang@yeah.net

Key words: atrial fibrillation, atrial calpains, structural remodeling, aging pathophysiological alterations in normal aged atria may therefore produce a substrate that is conducive to $\mathrm{AF}$.

\section{Introduction}

Atrial fibrillation (AF) is the most common cardiac arrhythmia. It affects millions of individuals worldwide and the incidence increases with age $(1,2)$. The increased number of cases of $\mathrm{AF}$ in the elderly may be due to several factors, including disease, fibrosis and/or age-related changes in cellular electrophysiological properties, which are likely to lead to a disturbance in atrial activation and repolarization (3-6). Calcium regulation is commonly implicated in numerous forms of injury that may occur during cellular aging. Altered calcium homeostasis has been correlated with age-related phenomena $(5,7,8)$. Calpains are calcium-dependent enzymes that are readily activated by elevated cellular calcium levels. In addition, calcium overload is involved in the pathogenesis of AF (9-11) and is also responsible for the initiation of other short-term adaptation mechanisms through the inactivation of the functional L-type $\mathrm{Ca}^{2+}$ current $\left(\mathrm{I}_{\mathrm{Ca}-\mathrm{L}}\right)(12,13)$.

Theoretically, calpain activation may be a process that results in important cellular changes with aging and/or in AF. Calpains have been demonstrated to degrade cytoskeletal, contractile and L-type $\mathrm{Ca}^{2+}$ channel proteins involved in atrial remodeling in $\mathrm{AF}(12,13)$. The reduction in the expression of the L-type calcium channel alc subunit $\left(\mathrm{LVDCC}_{\mathrm{alc}}\right)$ is suggested to be important in electrical remodeling in $\operatorname{AF}(9,14,15)$. This study aimed to investigate the correlation between the change in the expression of atrial calpains (calpain 1, calpain 2 and calpastatin) and cellular alterations in canines. In particular, the characteristic reduction in $\mathrm{LVDCC}_{\text {alc }}$ in left atrial cells and the accelerated fibrosis and apoptosis that occur with aging and/or in AF (induced by chronic rapid atrial pacing) were investigated.

\section{Materials and methods}

Animals. Fourteen adult (age, 1-3 years) and 14 aged (age, $>8$ years) mongrels, weighing $18-26 \mathrm{~kg}$ each, were obtained from the Animal Center of Xinjiang Medical University 
(Xinjiang, China). The ages of the canines were estimated by a veterinarian based on standard measures for age, including dentition, coat, eyes and musculoskeletal and conformational descriptors. The canines were kept in a temperature-controlled environment under a 12-h light/dark cycle and fed a standard laboratory diet and water ad libitum. The Animal Care and Use Committee of the Xinjiang Medical University (Xinjiang, China) approved all experiments in accordance with the Declaration of the National Institutes of Health Guide for Care and Use of Laboratory Animals (16).

Six-lead electrocardiogram (ECG) measurements were performed on resting, conscious canines to confirm sinus rhythm (SR). In addition, echocardiograms were performed to exclude canines with structural heart disease. Canines from both age groups were randomly divided into 4 groups $(n=7)$; the adult SR, the aged SR, the adult AF and the aged AF groups. AF was induced by chronic rapid atrial pacing and was defined as persistence of AF for at least 5 days.

Induction of $A F$. In total, seven adult and seven aged dogs underwent the procecure. Animals were anesthetized with pentobarbital sodium (30 mg/kg, i.v.; Jinyao Company, Tianjin, China) and ventilated with isoflurane (1.5-2\%; Yapei Company, Shanghai, China), and $\mathrm{O}_{2}$ (2 1/min). Morphine sulfate $(0.15 \mathrm{mg} / \mathrm{kg}$; The First Pharmaceutical Company, Shenyang, China) was injected into the epidural space to maintain postoperative analgesia. Using sterile techniques, a right intercostal thoracotomy was performed, the pericardium was opened and the heart was suspended in a pericardial cradle. A lead was attached to the epicardium of the left atrial appendage, tunneled subcutaneously and connected to a Pulse Generator (Department of Electronic Engineering, Fudan University, Shanghai, China). Pulse generators were implanted in subcutaneous pockets on the left posterior chest wall. When the incisions had been closed and the canines had recovered from anesthesia, they were monitored for 2-3 days in the recovery room prior to being moved for routine care. The canines were prophylactically treated with cefazolin $(25 \mathrm{mg} /$ $\mathrm{kg}$, i.v.) twice daily for 2 days following surgery. They were allowed to stabilize for 1 week and were paced at $600 \mathrm{bpm}$ from the left atrial appendage to induce persistent AF. Canines were used for the in vitro study when they exhibited persistent AF for $\geq 5$ days.

Atrial myocyte preparation. Subsequent to the experiments, the canines were anesthetized with pentobarbital sodium (30 mg/kg, i.v.) and sternotomies were performed. The hearts were quickly removed and sections of the left atrial wall samples were rapidly frozen in liquid nitrogen and stored separately at $-80^{\circ} \mathrm{C}$ for further analysis. One aliquot of each tissue sample was used to investigate mRNA expression of target genes and another was used to determine the protein levels. In addition, the hearts were rinsed in oxygenated $\mathrm{Ca}^{2+}$-free Tyrode's solution [137 mmol/1 NaCl, $5.4 \mathrm{mmol} / \mathrm{KCl}$, $1.0 \mathrm{mmol} / 1 \mathrm{MgCl}_{2}, 0.33 \mathrm{mmol} / 1 \mathrm{NaH}_{2} \mathrm{PO}_{4}, 10 \mathrm{mmol} / 1 \mathrm{HEPES}$

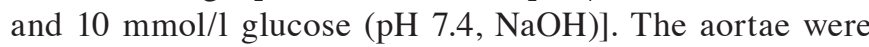
cannulated and the hearts were retrogradely perfused on a Langendorff apparatus (HEKA Instruments, Inc., Lambrecht, Germany) at $37^{\circ} \mathrm{C}$. A perfusion of $\mathrm{Ca}^{2+}$-free Tyrode's solution for $5 \mathrm{~min}$ was followed by $\mathrm{Ca}^{2+}$-free Tyrode's solution containing $0.03 \%$ collagenase II (Worthington Biochemical, Lakewood, NJ, USA) and 1\% bovine serum albumin (BSA) for $35 \mathrm{~min}$. The left atria were dissected, minced and gently triturated with a pipette in a $\mathrm{Ca}^{2+}$ Tyrode's solution containing $1 \% \mathrm{BSA}$ at $37^{\circ} \mathrm{C}$ for $10 \mathrm{~min}$. The cells were filtered through a 200- $\mu$ m nylon mesh (Chenjie Company, Shanghai, China) and resuspended in the Tyrode's solution, in which the $\mathrm{Ca}^{2+}$ concentration was gradually increased to $1.0 \mathrm{mmol} / \mathrm{l}$. Only cells with a rod-shaped morphology and clear cross-striation were used for the experiments.

Cellular electrophysiological studies. Left atrium cells were maintained in a 1-ml bath, continuously superfused with normal Tyrode's solution (2-3 ml/min) containing $137 \mathrm{mmol} / \mathrm{l}$ $\mathrm{NaCl}, 5.4 \mathrm{~m} \mathrm{~mol} / 1 \mathrm{KCl}, 1.0 \mathrm{mmol} / 1, \mathrm{MgCl}_{2} 1.8 \mathrm{mmol} / \mathrm{C} \mathrm{CaCl}_{2}$, $0.33 \mathrm{mmol} / 1 \mathrm{NaH}_{2} \mathrm{PO}_{4}, 10 \mathrm{mmol} / 1 \mathrm{HEPES}$ and $10 \mathrm{mmol} / 1$ glucose (the $\mathrm{pH}$ was adjusted with $\mathrm{NaOH}$ to 7.4) and bubbled with $100 \% \mathrm{O}_{2}$. Membrane currents and action potentials (APs) were recorded using whole-cell patch clamp techniques with an EPC 10/n Double amplifier (HEKA Instruments, Inc.) and Patchmaster software (HEKA). Patch pipette resistances ranged from 2.0 to $3.0 \mathrm{M} \Omega$ when filled with an internal solution. The AP was recorded in current-clamp mode. The solution for AP recording contained $137 \mathrm{mmol} / \mathrm{l} \mathrm{NaCl}, 5.4 \mathrm{mmol} / \mathrm{l} \mathrm{KCl}$, $1.0 \mathrm{mmol} / 1 \mathrm{MgCl}_{2}, 1.8 \mathrm{mmol} / 1 \mathrm{CaCl}_{2}, 10 \mathrm{mmol} / 1 \mathrm{HEPES}$ and $20 \mathrm{mmol} / \mathrm{l}$ glucose (the $\mathrm{pH}$ was adjusted with $\mathrm{KOH}$ to 7.4). The internal solution for the electrode for the AP recording contained $140 \mathrm{mmol} / 1 \mathrm{KCl}, 2.0 \mathrm{mmol} / 1 \mathrm{MgCl}_{2}, 2.0 \mathrm{mmol} / 1$ egtazic acid, $5.0 \mathrm{mmol} / 1 \mathrm{HEPES}, 5 \mathrm{mmol} / \mathrm{l}$ EGTA and $4.0 \mathrm{mmol} / 1 \mathrm{ATP}-\mathrm{Na}_{2}$ (the $\mathrm{pH}$ was adjusted with $\mathrm{KOH}$ to 7.4). The calcium currents were recorded in the voltage-clamp mode. The external solution for the $\mathrm{I}_{\mathrm{Ca}-\mathrm{L}}$ recording contained $137 \mathrm{mmol}$ choline-Cl, $2.0 \mathrm{mmol} \mathrm{CaCl}_{2}, 1.0 \mathrm{mmol} \mathrm{MgCl}_{2}$, $5 \mathrm{mmol}$ HEPES, $10 \mathrm{mmol}$ glucose, $4.6 \mathrm{mmol} \mathrm{CsCl}, 10 \mathrm{mmol}$ TEA-Cl and 5 mmol 4-AP (pH 7.30, CsOH). The internal solution for $\mathrm{I}_{\mathrm{Ca}-\mathrm{L}}$ recording contained $120 \mathrm{mmol} \mathrm{CsCl}, 1.0 \mathrm{mmol}$ $\mathrm{MgCl}_{2}, 5.0 \mathrm{mmol} \mathrm{MgATP}, 10 \mathrm{mmol}$ BAPTA, $10 \mathrm{mmol}$ HEPES and 10 mmol TEA-Cl (pH 7.30, CsOH). In the present study, data acquisition began $10 \mathrm{~min}$ following membrane rupture. $\mathrm{I}_{\mathrm{Ca}-\mathrm{L}}$ magnitudes were normalized by each cellular membrane capacitance $(\mathrm{pF})$ and expressed as current density $(\mathrm{pA} / \mathrm{pF})$. Recordings were filtered at low pass $(2 \mathrm{~Hz})$ and high pass $(30 \mathrm{~Hz})$. Activation voltage dependence was assessed by depolarization-induced currents, with the driving force corrected by dividing membrane potential (MP)-Erev, where Erev is the voltage axis intercept of the ascending limb of the current-voltage relation. Inactivation was assessed with 1 -sec prepulses at $-60,-50,-40,-35,-30,-25,-20,-15,-10,0,10,20$, 30 and $40 \mathrm{mV}$, followed by $240-\mathrm{msec}$ test pulses to $+10 \mathrm{mV}$. The Boltzmann equation was used to fit data. $\mathrm{I}_{\mathrm{Ca}-\mathrm{L}}$ recovery was studied with paired $240-\mathrm{msec}$ pulses to $10 \mathrm{mV}(0.1 \mathrm{~Hz})$ delivered at progressively increasing interpulse intervals (P-P) of $3,5,8,10,20,40,60,80,160,300,500$ and 1000 msec.

Morphological evaluation. Tissues from the left atrial wall were immediately fixed with $4 \%$ paraformaldehyde at $4{ }^{\circ} \mathrm{C}$ and embedded in paraffin. Light microscopy was performed using 2- $\mu \mathrm{m}$ sections stained with hematoxylin and eosin, and Masson's trichrome stain (Yisha Biological Technology Co., Ltd., Shanghai, China). To quantify the extent of myolysis in 
the cardiomyocytes, at least two sections per atrial site and $\geq 200$ cells/section were observed. The extent of cell change was only analyzed in cells in which the nucleus was present in the plane of the section. The myolytic area of the cardiomyocytes was measured using a digital imaging system (Motic Images Advanced, Richmond, BC, Canada). Cells were scored as either mildly myolytic when myolysis involved $10-25 \%$ of the cytosol or severely myolytic when $>25 \%$ of the sarcomeres were absent.

For electron microscopy, ultrathin sections (50-100 nm) were cut from each sample, counterstained with uranium acetate and lead citrate and observed under a transmission electron microscope (Philips 201, Philips Scientific, Mahwah, NJ, USA) at high magnification (x10,000).

TUNEL assay. Sections were transferred to xylene and rehydrated in decreasing concentrations of alcohol. Slides were then incubated for $10 \mathrm{~min}$ at room temperature with $10 \mu \mathrm{g}$ proteinase K (Sigma-Aldrich, St. Louis, MO, USA) per $1 \mathrm{ml}$ of phosphate-buffered saline. Encanineenous peroxydase was inactivated by ImmunoPure peroxydase suppressor for 30 min (Pierce Biotechnology Inc., Rockford, IL, USA). Tissue sections were permeabilized with $1 \%$ Triton $\mathrm{X}-100$ at $4^{\circ} \mathrm{C}$ for $2 \mathrm{~min}$ and stained using an in situ cell detection system (POD, Boehringer Mannheim, Mannheim, Germany). DNA strand breaks were identified by labeling free 3'-OH termini with deoxyuridine triphosphate-fluorescein isothiocyanate using terminal deoxynucleotidyl transferase (Tdt) for terminal deoxynucleotidyl-transferase-mediated dUTP nick end labeling (TUNEL) analysis. The incorporated fluorescein was detected by anti-fluorescein antibody Fab fragments from sheep conjugated with horseradish peroxydase (POD). Following the reaction with the metal-enhanced DAB substrate (Boehringer Mannheim), the sections were counterstained with hematoxylin. For positive controls, fixed and permeabilized sections were incubated with DNase I $(1 \mu \mathrm{g} / \mathrm{ml})$ for $10 \mathrm{~min}$ at room temperature. For negative controls, sections were incubated in labeling solution without Tdt. The percentage of TUNEL-positive nuclei was calculated by examining 50 randomly selected fields/section, containing 700 cells, at high magnification (x400).

Gene expression. Total RNA was extracted from samples of the left artium appendage using TRIzol (Invitrogen Life Technologies, Carslbad, CA, USA). The expression levels of the target genes were measured via quantitative (q)PCR using SYBR-Green qPCR Master mix (Bio-Rad, Hercules, CA, USA) in a $20-\mu 1$ reaction volume containing $50 \mathrm{ng}$ cDNA. All reactions were performed in triplicate and included a negative control. PCR reactions were conducted using the ABI Prism 7500 Sequence Detection System (Invitrogen Life Technologies). Cycling conditions were $2 \mathrm{~min}$ at $50^{\circ} \mathrm{C}, 10 \mathrm{~min}$ at $95^{\circ} \mathrm{C}, 40$ cycles for $15 \mathrm{sec}$ at $95^{\circ} \mathrm{C}$ and $1 \mathrm{~min}$ at $60^{\circ} \mathrm{C}$. Relative quantification of mRNA levels was conducted using the 7500 system software (Invitrogen Life Technologies), which uses the comparative method. Fluorescence signals were normalized to the housekeeping gene $\beta$-actin. The comparative threshold $(\mathrm{Ct})$ cycle method was used $(\Delta \mathrm{Ct})$ for relative quantification. For every sample, each gene was quantified in duplicate in three separate experiments. The values were averaged and then used for the $2^{-\Delta \Delta C t}$ calculation, where $2^{-\Delta \Delta C t}$ corresponds to expression relative to that of $\beta$-actin. The expected size of the amplicons were confirmed by gel electrophoresis. The sequences of the genes studied were obtained from GenBank, and the primers were designed using the Primer 5.0 software (Invitrogen Life Technologies). The following primer sequences, amplicon size and annealing temperatures were used: Forward, 5'-AAGGA CCTGTATGCCAACACA-3' and reverse, 5'-ATCCACACA GAATACTTGCGTT-3' (152 bp, 57 ${ }^{\circ} \mathrm{C}$ ) for $\beta$-actin; forward, 5'-GACGCTATGGGCTATGAGTTAC-3' and reverse, 5'-AGTCCAGGTAGCCCTTTAGGT-3' (199 bp, 58 ${ }^{\circ} \mathrm{C}$ ) for $\mathrm{LVDCC}_{\mathrm{a} 1 \mathrm{c}}$; forward, 5'-TCACCCTCAATGACACGCTT-3' and reverse, 5'-GCAGCAGGTCATCCACGA-3' $\left(135 \mathrm{bp}, 58^{\circ} \mathrm{C}\right)$ for calpain 1; forward, 5'-TCACCCTCATGAGTTAC3' and reverse, 5'-ATCCACACTGCCAACACA-3' (125 bp, 57.5 $\mathrm{C}$ ) for calpain 2; and forward, 5'-GCTGGTTCCTCAAACACT TCA-3' and reverse, 5'-CATCGTCCAGTTCTTTGTTGTC-3' $\left(154 \mathrm{bp}, 57.2^{\circ} \mathrm{C}\right.$ ) for calpastatin.

Assessment of protein expression. Membrane proteins were extracted from tissue samples of the left atrium (LA) with $5 \mathrm{mmol} / \mathrm{l} \mathrm{Tris-HCl}(\mathrm{pH} 7.4), 2 \mathrm{mmol} / \mathrm{l}$ EDTA, $5 \mu \mathrm{g} / \mathrm{ml}$ leupeptin, $10 \mu \mathrm{g} / \mathrm{ml}$ benzamidine and $5 \mu \mathrm{g} / \mathrm{ml}$ soybean trypsin inhibitor. Subsequent to this, tissue homogenization was conducted. All procedures were performed at $4{ }^{\circ} \mathrm{C}$. Equal quantities (100 $\mu \mathrm{g} / \mathrm{sample})$ of LA membrane proteins were separated on $8 \%$ sodium dodecyl sulfate-polyacrylamide gel electrophoresis gels and transferred on polyvinylidene difluoride membranes. The membranes were blocked in 5\% non-fat dry milk in TBST (tris-buffered saline with Tween 20; $50 \mathrm{mmol} / 1$ Tris-HCl, 500 mmol/1 NaCl; pH 7.5, 0.05\% Tween-20) for $2 \mathrm{~h}$ and incubated with primary antibody (dilution, 1:500) in 5\% non-fat dry milk in TBST for $4 \mathrm{~h}$ at room temperature. The membranes were then incubated with the following antibodies: rabbit polyclonal anti-LVDCC ${ }_{\mathrm{alc}}$ (Santa Cruz Biotechnology, Santa Cruz, CA, USA) and rabbit polyclonal anti-calpain 1, -calpain 2 and -calpastatin (Santa Cruz Biotechnology). The membranes were washed three times in TBST, reblocked in 5\% non-fat dry milk and TBST for 15 min and incubated with horseradish peroxidase (HRP)-conjugated goat anti-rabbit antibodies (dilution, 1:5,000) in 5\% non-fat dry milk in TBST (40 min). Immunoreactive bands were detected by Immun-Star HRP Substrate (Bio-Rad) and quantified through densitometry analysis using an ImageQuant 350 imager and ImageQuant TL-1 software (GE Healthcare, Little Chalfront, UK). Anti- $\beta$-actin antibody (Santa Cruz Biotechnology) was used to control equal protein loading and normalize ion channel protein band intensity. All western blot analysis target bands were expressed quantitatively by normalization to the control band in the same lane. Western blot analysis band intensities were expressed in optical density units, according to the densitometric analysis of band intensity following background subtraction, divided by the $\beta$-actin signal intensity for the same sample.

Statistical analysis. The AP properties measured include maximum diastolic potential (MDP), amplitude of phase 0 (APA), maximum upstroke velocity, potential at the peak of the plateau and AP duration to $90 \%$ repolarization $\left(\mathrm{APD}_{90}\right)$. Quantitative data were presented as the mean \pm standard 
Table I. AP characteristics recorded in adult and aged atria in SR and AF at a cycle length of 2,000 msec.

\begin{tabular}{llllll}
\hline Group & $\mathrm{n}$ & MDP $(\mathrm{mV})$ & APA $(\mathrm{mV})$ & Plateau $(\mathrm{mV})$ & APD \\
\hline SR adult & 24 & $-78.8 \pm 0.8$ & $109.8 \pm 1.4$ & $-4.0 \pm 0.7$ & $320.0 \pm 7.9 .$. \\
SR aged & 30 & $-79.2 \pm 1.4$ & $110.5 \pm 4.9$ & $-7.5 \pm 1.7^{\mathrm{a}}$ & $340.5 \pm 10.1^{\mathrm{a}}$ \\
AF adult & 28 & $-71.8 \pm 0.9^{\mathrm{b}}$ & $121.8 \pm 1.1^{\mathrm{b}}$ & $-6.4 \pm 1.1^{\mathrm{b}}$ & $297.0 \pm 5.6^{\mathrm{b}}$ \\
AF aged & 26 & $-72.2 \pm 1.2^{\mathrm{b}}$ & $122.5 \pm 2.9^{\mathrm{b}}$ & $-9.8 \pm 1.1^{\mathrm{b}}$ & $300.5 \pm 7.1^{\mathrm{b}}$
\end{tabular}

Data are presented as the mean $\pm \mathrm{SD}$. ${ }^{\mathrm{a}} \mathrm{P}<0.05$ vs. the adult in $\mathrm{SR}$ group; ${ }^{\mathrm{b}} \mathrm{P}<0.05$ compared with $\mathrm{SR}$ in the same age group. $\mathrm{n}$, number of cells obtained from the seven canines in each group; SR, sinus rhythm; AF, atrial fibrillation; MDP, maximum diastolic potential; APA, action potential amplitude; Plateau, AP plateau potential; $\mathrm{APD}_{90}$, AP duration to $90 \%$ repolarization.

A

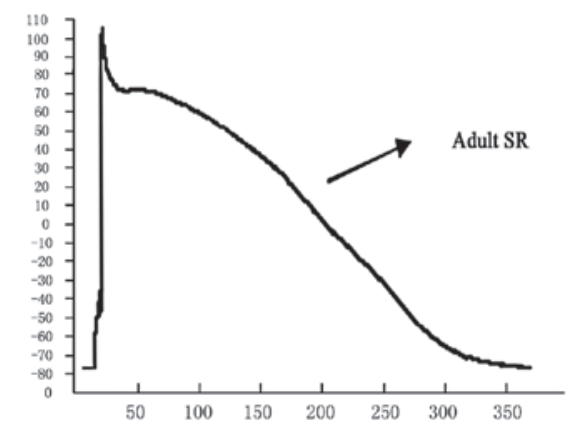

C

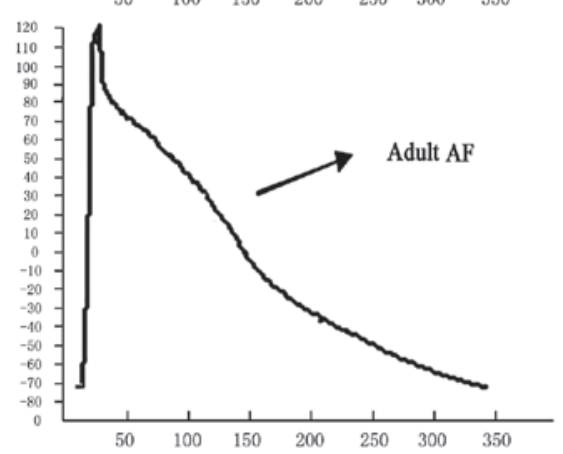

B

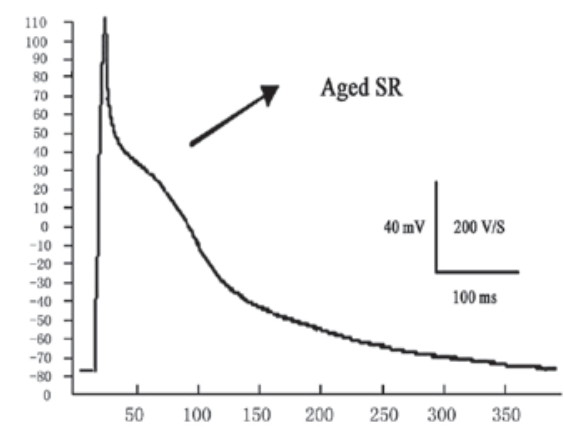

D

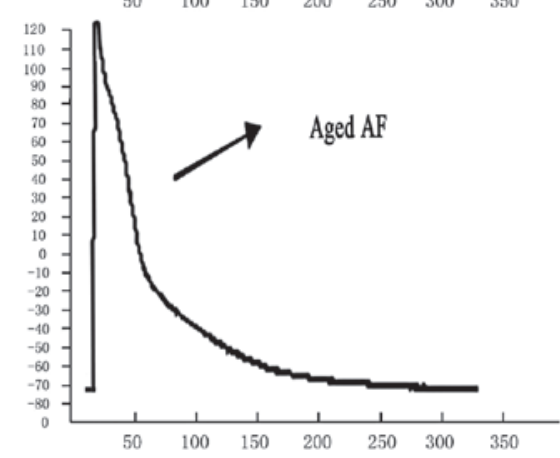

Figure 1. Action potential (AP) recordings from left atrium (LA) cardiomyocytes in (A) adult sinus rhythm (SR), (B) aged SR, (C) adult atrial fibrillation (AF) and (D) aged AF groups. (SR adults, 24 cells; SR aged, 30 cells; AF adults, 28 cells; and AF aged, 26 cells from the 7 canines in each group, respectively).

deviation. Comparisons between the quantitative and qualitative data were performed using a t-test and the $\chi^{2}$ method, respectively. SPSS 10.0 software (SPSS Inc., Chicago, IL, USA) was used for statistical analysis. $\mathrm{P}<0.05$ was considered to indicate a statistically significant difference.

\section{Results}

ECG data. The ECGs of the aged canines manifested a longer $\mathrm{P}$-wave duration and dispersion than adult canines $(66.1 \pm 6.4$ versus $75.9 \pm 5.3 \mathrm{msec}$ and $19.1 \pm 4.1$ versus $26.7 \pm 3.1 \mathrm{msec}$, respectively; $\mathrm{n}=7 ; \mathrm{P}<0.05)$. Other variables did not differ. There was no significant difference identified between the two groups at the time of persistent AF onset; the adult canines

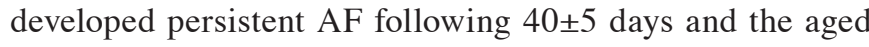
canines following $52 \pm 7$ days of atrial pacing $(\mathrm{P}>0.05)$.

Changes in AP characteristics. Representative recordings and summary data for the predominant AP parameters of adult and aged canines in SR and those with AF are shown in Table I and Fig. 1. Cardiomyocytes from aged atria exhibited longer $\mathrm{APD}_{90}$, a significantly lower AP plateau potential compared with adult canines and no significant differences in MDP and APA. APD 90 was shortened with AF in the adult and aged groups with increased shortening in the aged group, which resulted in no difference between $\mathrm{APD}_{90}$ in the two $\mathrm{AF}$ groups. AF led to a higher MDP, a significant increase of APA and a lower AP plateau potential in the two age groups. AF was associated with significant depolarization of the cellular membrane in adult and aged LA. The extent of depolarization was the same in the two AF groups, resulting in increased depolarization in the adult cardiomyocytes compared with that in aged cardiomyocytes.

Changes in $I_{C a-L}$ characteristics. Typical recordings of $\mathrm{I}_{\mathrm{Ca}-\mathrm{L}}$ and comparative predominant $\mathrm{I}_{\mathrm{Ca}-\mathrm{L}}$ parameters in adult and aged canines in SR and those with AF are shown in Table II and Fig. 2. Aged LA cardiomyocytes demonstrated lower 
Table II. Electrophysiological characteristics of $\mathrm{I}_{\mathrm{Ca}-\mathrm{L}}$ between adult and aged LA in SR and AF.

\begin{tabular}{|c|c|c|c|c|c|c|c|}
\hline \multirow[b]{2}{*}{ Group } & \multirow[b]{2}{*}{$\mathrm{n}$} & \multirow{2}{*}{$\begin{array}{l}\mathrm{I}_{\mathrm{Ca}-\mathrm{L}} \text { density } \\
(\mathrm{pA} / \mathrm{pF})\end{array}$} & \multicolumn{2}{|c|}{ Steady-state activation } & \multicolumn{2}{|c|}{ Steady-state inactivation } & \multirow{2}{*}{$\begin{array}{l}\text { Monoexponential recovery } \\
\text { time constant (msec) }\end{array}$} \\
\hline & & & $\mathrm{V}_{0.5}(\mathrm{mV})$ & $\mathrm{k}(\mathrm{mV})$ & $\mathrm{V}_{0.5}(\mathrm{mV})$ & $\mathrm{k}(\mathrm{mV})$ & \\
\hline SR adult & 14 & $-14.1 \pm 0.8$ & $-7.1 \pm 1.5$ & $5.7 \pm 0.4$ & $-23.1 \pm 2.1$ & $6.2 \pm 0.3$ & $51.9 \pm 3.3$ \\
\hline SR aged & 16 & $-8.1 \pm 0.5^{\mathrm{a}}$ & $-6.7 \pm 2.8$ & $5.5 \pm 0.5$ & $-22.9 \pm 3.3$ & $6.4 \pm 0.5$ & $53.1 \pm 3.1$ \\
\hline AF adult & 15 & $-9.4 \pm 0.7^{\mathrm{b}}$ & $-6.9 \pm 1.2$ & $5.1 \pm 0.3$ & $-22.1 \pm 1.9$ & $6.2 \pm 0.3$ & $51.2 \pm 2.3$ \\
\hline AF aged & 19 & $-5.9 \pm 0.3^{\mathrm{b}}$ & $-6.8 \pm 2.1$ & $5.9 \pm 0.3$ & $-21.9 \pm 2.3$ & $6.8 \pm 0.6$ & $52.1 \pm 5.1$ \\
\hline
\end{tabular}

Values are presented as the mean $\pm \mathrm{SD} . \mathrm{V}_{0.5}$ and $\mathrm{k}$ are average values of voltage at half maximal availability and slope factor as determined by the Boltzmann equation. $\mathrm{I}_{\mathrm{Ca}-\mathrm{L}}$ current densities at maximal voltage $(-90 \mathrm{mV})$ are shown. ${ }^{\mathrm{a}} \mathrm{P}<0.05$ vs. the adult in $\mathrm{SR}$ group. ${ }^{\mathrm{b}} \mathrm{P}<0.05$ vs. compared with SR in the same age group. $n$, number of cells obtained from the seven canines in each group; $\mathrm{I}_{\mathrm{Ca}-\mathrm{L}}$, L-type Ca ${ }^{2+}$ current; LA, left atrium; SR, sinus rhythm; AF, atrial fibrillation.
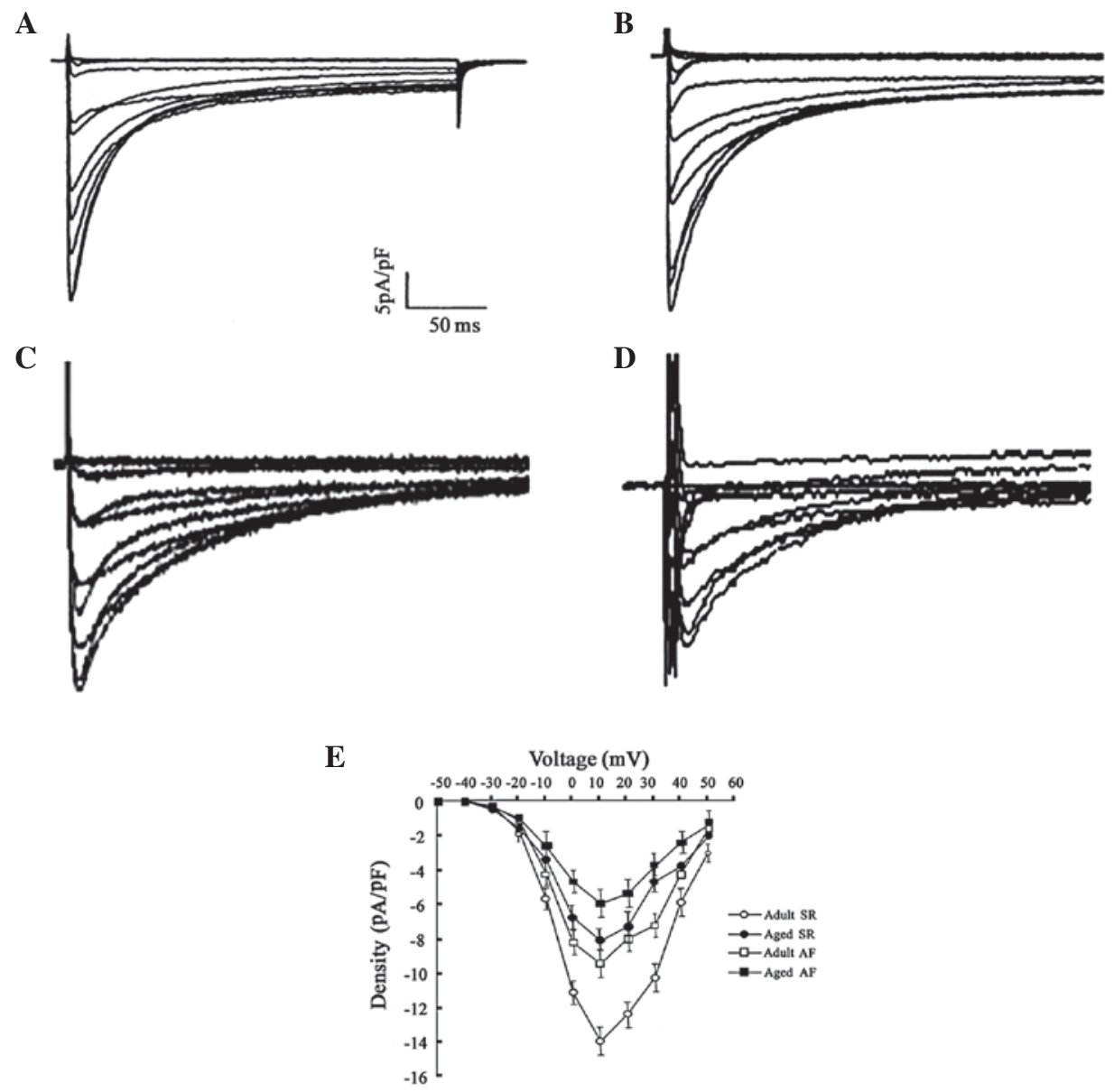

Figure 2. L-type $\mathrm{Ca}^{2+}$ current $\left(\mathrm{I}_{\mathrm{Ca}-\mathrm{L})}\right.$ tracings between adults and aged left atrium (LA) in sinus rhythm (SR) and atrial fibrillation (AF), with a holding voltage of $-70 \mathrm{mV}$ to various test voltages. (A) Adult sinus rhythm (SR), (B) aged SR, (C) adult atrial fibrillation (AF) and (D) aged AF groups. (E) Average peak $\mathrm{I}_{\mathrm{Ca}-\mathrm{L}}$ density in adult and aged cells. All data were collected simultaneously following establishment of whole cell configuration (adults, $17 \pm 0.8$ min and aged, $18 \pm 1.1 \mathrm{~min}$ ). (SR adults, 14 cells; SR aged, 16 cells; AF adults, 15 cells; and AF aged, 19 cells from the 7 canines in each group, respectively).

peak $\mathrm{I}_{\mathrm{Ca}-\mathrm{L}}$ densities than adult LA cells. In addition, this decrease was observed in the adult and aged AF groups; however, it was lowest in the aged groups. Activation voltage dependence exhibited no significant difference in the half-activation voltage and slope factor of each group. Furthermore, no significant difference in the half-inactivation voltage and slope factor of each group was observed.
However, this current reduction during aging and in AF was not accompanied by a significant change in its recovery time from inactivation.

Fibrosis change. As shown in Fig. 3, compared with those in the adult group, the myocardial fibers of tissue from the aged group appeared to be more compact and were closer together. 

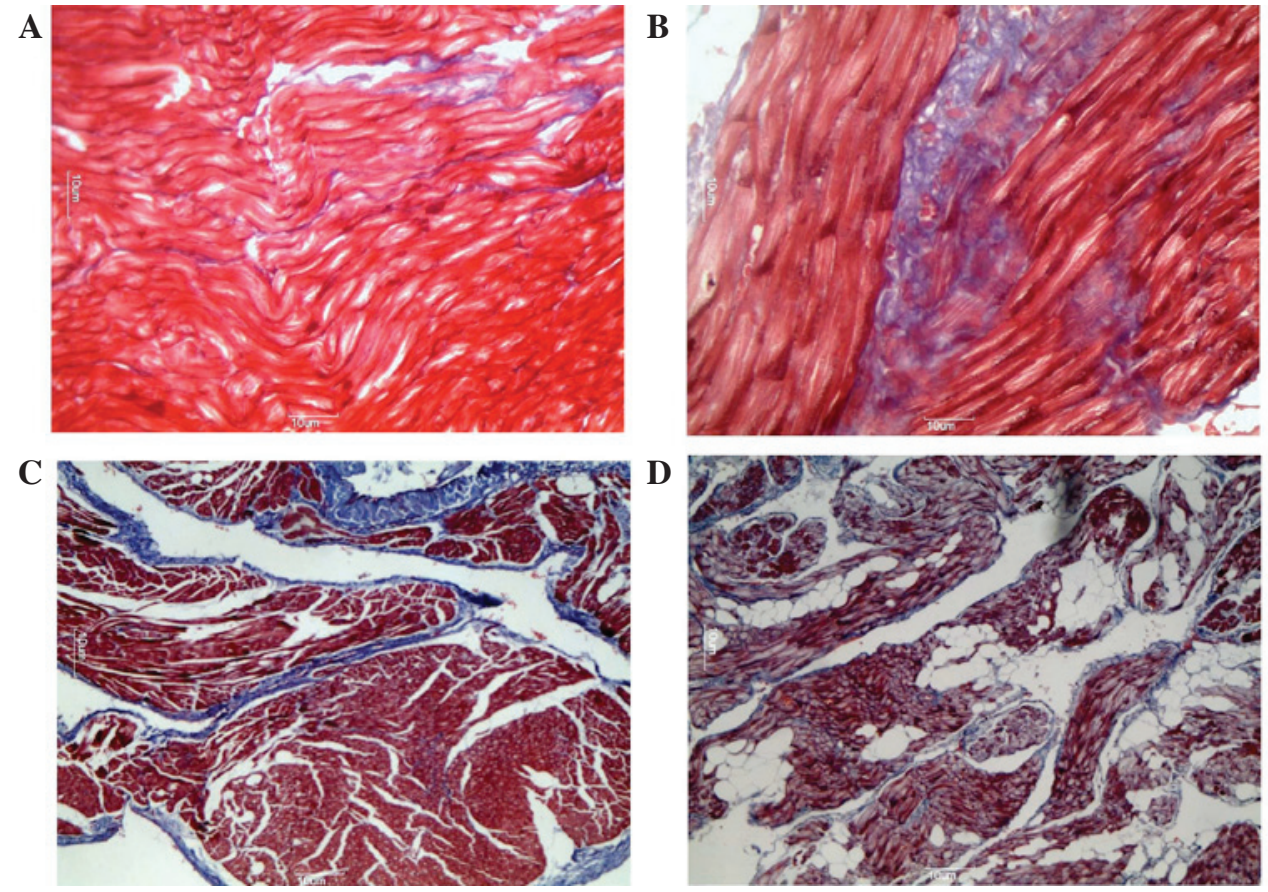

Figure 3. Representative sections of the left atrium (LA) free wall from the four groups of canines showing myocytes and collagen. The circular, clear spaces are interstitial fat. (A) Adult sinus rhythm (SR), (B) aged SR, (C) adult atrial fibrillation (AF) and (D) aged AF groups. Images stained using Masson's trichrome stain (original magnification, $\mathrm{x} 160$ ).
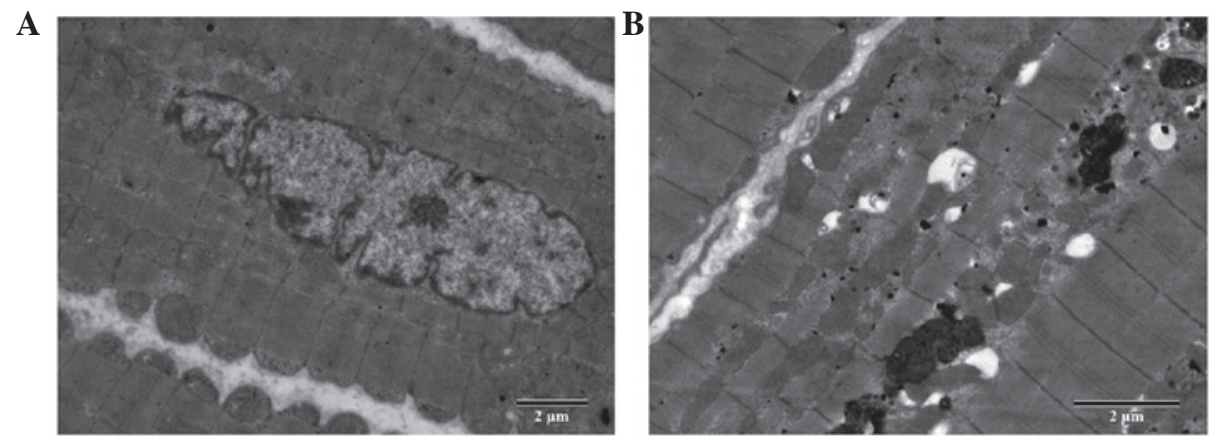

C
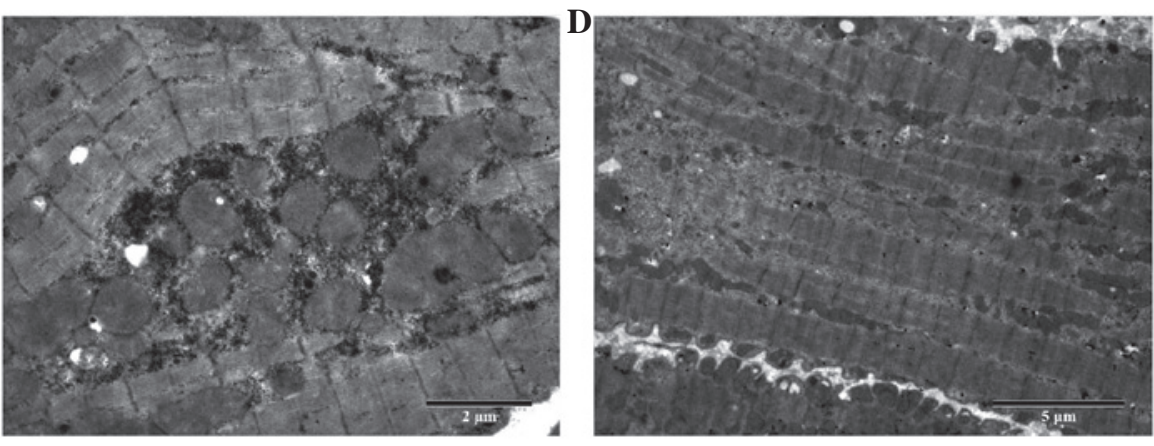

Figure 4. Typical examples of ultrastructural changes in atrial myocytes of the left atrium (LA) free wall from the four study groups. (A) Adult sinus rhythm (SR), (B) aged SR, (C) adult atrial fibrillation (AF) and (D) aged AF groups. Images obtained using electron microscopy (original magnification, x10,000).

Muscle bundles were separated by large strands of connective tissue and a significantly higher deposition of connective tissue was observed $(4.1 \pm 0.9$ versus $8.4 \pm 1.0 \%$; $n=15 ; \mathrm{P}<0.05)$. Moreover, the degree of myocardial fiber disarray was greater in the adult $(4.1 \pm 0.9$ versus $14.7 \pm 2.1 \% ; \mathrm{n}=15 ; \mathrm{P}<0.01)$ and aged $(8.4 \pm 1.0$ versus $18.2 \pm 2.4 \% ; \mathrm{n}=15 ; \mathrm{P}<0.01)$ groups with $\mathrm{AF}$ than that in the corresponding groups in SR. Moreover, the degree of myocardial fiber disarray among muscle bundles was greater in the aged group with AF than in the adult group with $\mathrm{AF}(14.7 \pm 2.1$ versus $18.2 \pm 2.4 \%$; $\mathrm{n}=15 ; \mathrm{P}<0.05)$.

Cell ultrastructural changes. The ultrastructure of the atrial myocardium was observed by electron microscopy and representative transmission electron micrographs are shown in Fig. 4. Atrial myocytes of the LA wall from the adult canines exhibited a regular sarcomere organisation, uniformly sized 

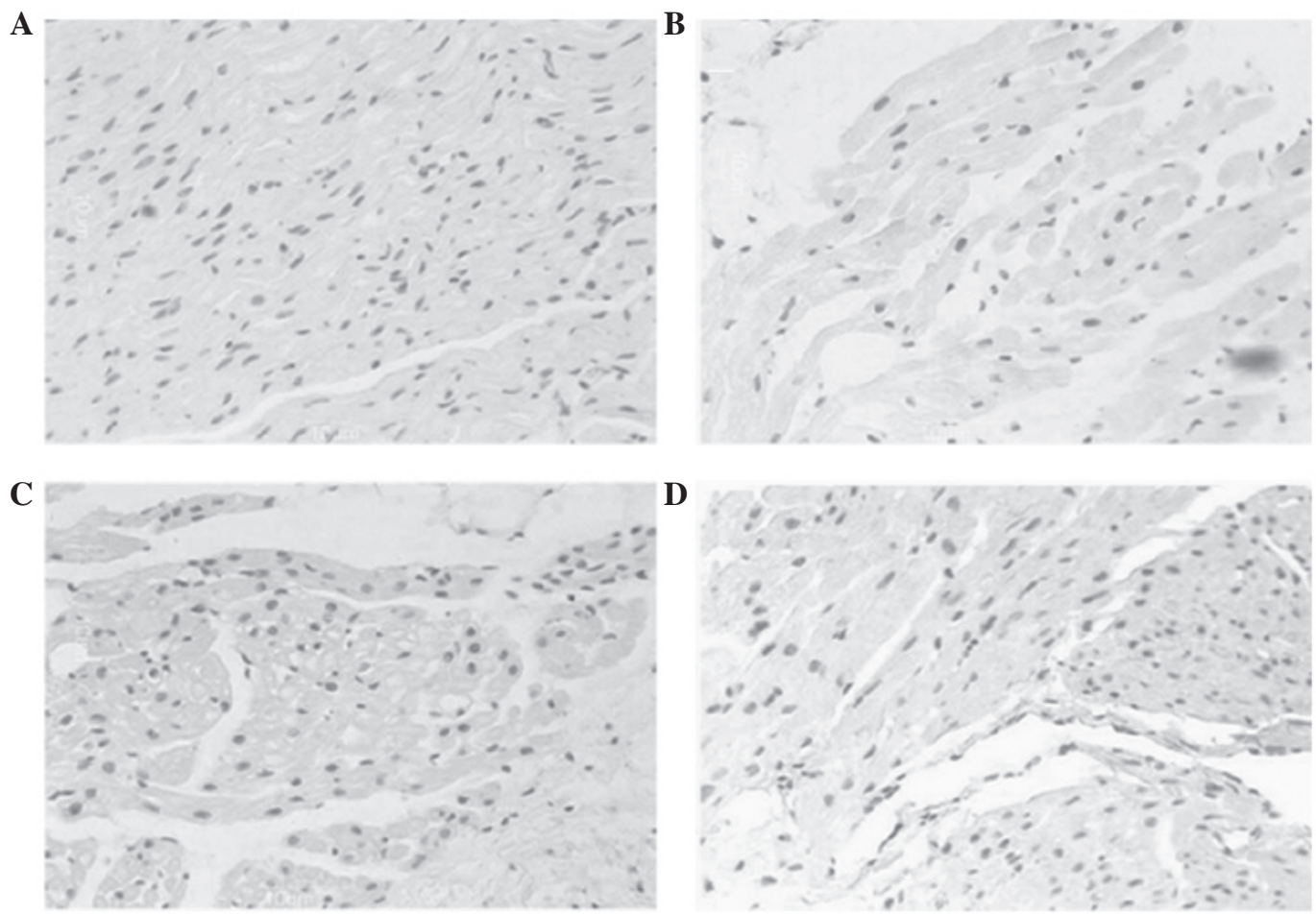

Figure 5. Staining of tissue sections from (A) adult, (B) aged, (C) adult atrial fibrillation (AF), (D) aged AF groups with terminal deoxynucleotidyl-trasferasemediated dUTP nick end labeling (TUNEL). Scale bar, $20 \mu \mathrm{m}$. Original magnification, $\mathrm{x} 400$.

mitochondria and nuclei showing normal clumping of chromatin at the nuclear membrane $(n=3$, samples from randomly selected adult canines) (Fig. 4A). Atrial myocytes of the LA wall from the aged canines exhibited an abnormal ultrastructure with mild and severe sarcomere degeneration, swelling of several mitochondria with a reduction in the density and organisation of the cristae, karyopyknosis with chromatin margination to the nuclear membrane, expanded endoplasmic reticulum, increased glucogen and mild compact and close myocardial fibers $(n=3$, samples from randomly selected aged canines) (Fig. 4B). Atrial myocytes of the LA wall from the adult canines with AF appeared to show a more abnormal ultrastructure, including severe sarcomere degeneration, increased mitochondrial swelling, karyopyknosis indicating cell apoptosis, several secondary lysosomes, expanded endoplasmic reticulum, decreased glucogen and irregular and disorderly myocardial fibers $(n=3$, samples from randomly selected adult canines with AF) (Fig. 4C). Atrial myocytes of the LA wall from the aged canines with AF also exhibited an abnormal ultrastructure, including more severe sarcomere degeneration, mitochondria with the presence of vacuoles, increased karyopyknosis indicating cell apoptosis, expanded endoplasmic reticulum and secondary lysosomes and disintegration of certain myofilaments $(n=3$, samples from randomly selected aged canines with AF) (Fig. 4D).

Apoptosis indices. As shown in Fig. 5, a higher percentage of myocytes with myolysis in aged canines exhibited TUNEL-positive nuclei compared with that of the adult group $(22.0 \pm 5.45$ versus $32.9 \pm 3.4 \% ; \mathrm{n}=12 ; \mathrm{P}<0.05)$. The majority of the nuclei were large in size with a uniform distribution of heterochromatin and exhibited weak TUNEL staining
(Fig. 5A and B). Moreover, the frequency of apoptosis significantly increased in the adult $(22.0 \pm 5.45$ versus $33.4 \pm 3.9 \%$; $\mathrm{n}=12 ; \mathrm{P}<0.01)$ and aged $(32.9 \pm 3.4$ versus $51.2 \pm 3.4 \% ; \mathrm{n}=12$; $\mathrm{P}<0.001)$ groups with AF, compared with their counterpart groups in SR. The frequency in the aged groups was greater than that in the adult groups. In addition, several nuclei decreased in size and stained strongly with TUNEL, indicating extensive DNA cleavage (Fig. 5C and D).

Left atrial mRNA and protein expression of $L V D C C_{a I c}$ and calpains. As shown in Tables III and IV, compared with the adult group, the mRNA and protein expression levels of $\mathrm{LVDCC}_{\mathrm{alc}}$ in the aged groups were significantly lower than those in the adult groups $(\mathrm{P}<0.05)$. The mRNA and protein expression of calpain 1, calpain 2 and calpastatin showed upregulation in the aged group; however, these were not significantly different between the two groups $(\mathrm{P}>0.05)$.

Compared with the control groups, the mRNA and protein expression of $\mathrm{LVDCC}_{\mathrm{alc}}$ was significantly lower and the mRNA and protein expression levels of calpain 1 were significantly higher in the adult and aged groups with AF $(\mathrm{P}<0.05)$. The aged group appeared to be the higher of the two AF groups $(\mathrm{P}<0.05)$. The protein level of $\mathrm{LVDCC}_{\mathrm{alc}}$ was negatively correlated with that of calpain $1(\mathrm{r}=-0.583, \mathrm{P}=0.019)$. No significant changes in the mRNA and protein levels of calpain 2 and calpastatin were observed between the SR and AF groups $(\mathrm{P}>0.05)$. In the adult and aged groups with $\mathrm{AF}$, the protein expression of calpain 1 was positively correlated with the degree of myocardial fiber disarray $(\mathrm{r}=0.421, \mathrm{P}=0.041$ and $\mathrm{r}=0.475, \mathrm{P}=0.036$, respectively) and directly correlated with the frequency of apoptosis $(\mathrm{r}=0.503, \mathrm{P}=0.043$ and $\mathrm{r}=0.528$, $\mathrm{P}=0.036$, respectively). 
Table III. The expression of mRNA in the left atrial myocardium in adult and aged LA in SR and AF.

\begin{tabular}{llllll}
\hline & & \multicolumn{3}{c}{ Expression } \\
\cline { 3 - 6 } Group & $\mathrm{n}$ & LVDCC $_{\mathrm{alc}}$ & Calpain 1 & Calpain 2 & Calpastain \\
\hline SR adult & 7 & $2.38 \pm 1.03$ & $1.45 \pm 0.68$ & $1.23 \pm 0.59$ & $1.38 \pm 0.71$ \\
SR aged & 7 & $1.17 \pm 0.75^{\mathrm{a}}$ & $1.79 \pm 0.75$ & $1.43 \pm 0.89$ & $1.47 \pm 0.84$ \\
AF adult & 7 & $0.27 \pm 0.25^{\mathrm{b}}$ & $2.53 \pm 0.85^{\mathrm{b}}$ & $1.48 \pm 0.78$ & $1.45 \pm 0.74$ \\
AF aged & 7 & $0.10 \pm 0.07^{\mathrm{b}}$ & $2.72 \pm 0.66^{\mathrm{b}}$ & $1.53 \pm 1.01$ & $1.71 \pm 0.62$
\end{tabular}

Values are presented as the mean \pm SD. n, Number of canines per group. ${ }^{\mathrm{a}} \mathrm{P}<0.05$ vs. the adult in $\mathrm{SR}$ group, ${ }^{\mathrm{b}} \mathrm{P}<0.05$ compared with $\mathrm{SR}$ in the same age group. LA, left atrium; SR, sinus rhythm; AF, atrial fibrillation; LVDCCa1c, L-type calcium channel alc subunit.

Table IV. The expression of protein in the left atrial myocardium in adult and aged LA in SR and AF.

\begin{tabular}{|c|c|c|c|c|c|}
\hline \multirow[b]{2}{*}{ Group } & \multirow[b]{2}{*}{$\mathrm{n}$} & \multicolumn{4}{|c|}{ Expression } \\
\hline & & $\mathrm{LVDCC}_{\mathrm{a} 1 \mathrm{c}}$ & Calpain 1 & Calpain 2 & Calpastain \\
\hline SR adult & 7 & $0.28 \pm 0.11$ & $0.39 \pm 0.13$ & $0.36 \pm 0.16$ & $0.42 \pm 0.16$ \\
\hline SR aged & 7 & $0.13 \pm 0.10^{\mathrm{a}}$ & $0.47 \pm 0.21$ & $0.39 \pm 0.09$ & $0.44 \pm 0.23$ \\
\hline AF adult & 7 & $0.13 \pm 0.01^{b}$ & $0.61 \pm 0.19^{b}$ & $0.41 \pm 0.20$ & $0.38 \pm 0.08$ \\
\hline AF aged & 7 & $0.07 \pm 0.05^{\mathrm{b}}$ & $0.78 \pm 0.31^{b}$ & $0.44 \pm 0.17$ & $0.45 \pm 0.62$ \\
\hline
\end{tabular}

Values are presented as the mean $\pm \mathrm{SD} . \mathrm{n}$, Number of canines per group. ${ }^{\mathrm{a}} \mathrm{P}<0.05$ vs. the adult in $\mathrm{SR}$ group, ${ }^{\mathrm{b}} \mathrm{P}<0.05$ compared with $\mathrm{SR}$ in the same age group. LA, left atrium; SR, sinus rhythm; AF, atrial fibrillation; LVDCCa1c, L-type calcium channel alc subunit.

\section{Discussion}

In this study, it was demonstrated that the most notable alteration with aging was a significant decrease in the AP plateau potential and $\mathrm{APD}_{90}$ was prolonged in aged LA cardiomyocytes. Moreover, P-wave duration and dispersion were significantly longer in aged canines. The results may reflect an aging-associated degree of slower conduction of the atria. Previous studies have demonstrated that $\mathrm{I}_{\mathrm{Ca}-\mathrm{L}}$ is reduced in aged canine right atria cardiomyocytes compared with that of adult canines (3); however, no published data are available concerning the effects of age on LA cardiomyocyte $\mathrm{I}_{\mathrm{Ca}-\mathrm{L}}$. The present study demonstrated that there was a significant reduction in peak $\mathrm{I}_{\mathrm{Ca}-\mathrm{L}}$ in aged canine LA cardiomyocytes, while decreased $\mathrm{LVDCC}_{\mathrm{a} 1 \mathrm{c}}$ protein levels may be a predominant reason for the reduced $\mathrm{I}_{\mathrm{Ca}-\mathrm{L}}$. However, the current reduction in aged atrial cardiomyocytes was not accompanied by a significant change in calcium channel availability or recovery from inactivation. The currents that determine the plateau level of AP in the atria are ultrarapid delayed rectifier potassium current $\left(\mathrm{I}_{\mathrm{Kur}}\right)$, outward potassium current $\left(\mathrm{I}_{\mathrm{to}}\right)$ and $\mathrm{I}_{\mathrm{Ca}-\mathrm{L}}(15,17)$. Therefore, a decrease in depolarizing current $\mathrm{I}_{\mathrm{Ca}-\mathrm{L}}$ or an increase in repolarizing currents $\left(\mathrm{I}_{\mathrm{Kur}}\right.$ and/or $\left.\mathrm{I}_{\mathrm{to}}\right)$ may lead to a lower plateau of AP. Thus, the results suggested that the decrease in $\mathrm{I}_{\mathrm{Ca}-\mathrm{L}}$ may be a mechanism for the low plateau potential in aged canine LA cardiomyocytes. The longer $\mathrm{APD}_{90}$ in aged atria suggested certain aging-induced changes of delayed rectifier potassium currents $\left(\mathrm{I}_{\mathrm{K}}\right)$ or may be a consequence of the low plateau potential in aged canines.
Previous studies demonstrated that negative plateau potentials exhibited a lower driving force for the conduction of early premature beats $(18,19)$. Therefore, the results of the present study suggested that the change in the AP in aged atria may lead to a decreased conduction of premature beats. Slow conduction of early premature impulses may further facilitate the onset of AF.

Numerous studies have demonstrated that AF remodels atrial electrophysiology, which facilitates AF recurrence $(20,21)$. The predominant electrophysiological characteristics of electrical remodeling are a reduction in the atrial refractory period and a loss of the APD adaptation to rate $(22,23)$. To date, studies have been performed in normal adult animals $(17,20,21)$. AF-induced electrophysiological remodeling in adults results from rapid atrial activation, and rapid atrial pacing produces similar AP changes. However, the mechanism of AP changes observed with this remodeling may differ, as shown in the present study. It was observed that there was a reduced $\mathrm{I}_{\mathrm{Ca}-\mathrm{L}}$ in persistent $\mathrm{AF}$ cardiomyocytes versus controls. The change was interpreted as a result of the reduced $L V D C C_{a 1 c}$ protein levels. It appears reasonable to suggest that calcium ion channel remodeling is the basis of the atrial electrical remodeling of AF. Based on the present results, it was demonstrated that $\mathrm{AF}$ led to a notable shortening of $\mathrm{APD}_{90}$, a higher MDP, a significant increase of APA and a significant decrease of AP plateau potential in the two age groups. AF-induced decreases in $\mathrm{APD}_{90}$ may be explained by the reduction in $\mathrm{I}_{\mathrm{Ca}-\mathrm{L}}$, as AF was associated with a significant depolarization of the cellular membrane in adult and aged LA. 
This membrane depolarization in AF may be a consequence of the decreased basal $\mathrm{I}_{\mathrm{Ca}-\mathrm{L}}$.

Structurally, the most notable change in the aged atria was the increased quantity of fibrous tissue interspersed between myocytes. These alterations were observed in fibrillating and aged atria. Cardiac fibrosis is characterized by the excessive accumulation of fibrillar collagen in the extracellular space. In addition, interstitial fibrosis is known to reduce electrical coupling in the heart (24) and it significantly increases the complexity of the myocardial architecture by electrically insulating cardiac cells and/or muscle bundles $(25,26)$. As a direct consequence, the typical uniform anisotropic conduction in the atrial myocardium is replaced by nonuniform anisotropic conduction $(27,28)$. Fibrosis preferentially affects lateral (or transverse) connections, rather than longitudinal cell-cell connections $(29,30)$, resulting in a slower, zigzag transverse propagation $(31,32)$. Thus, a premature response occurring in the aged atrial myocardium has a higher probability of undergoing unidirectional block from an imbalance between source/sink currents and initiating re-entry due to the underlying arrhythmogenic substrate, which is produced as a result of electrical and/or structural remodeling $(5,14,33)$.

Notable cytoarchitectural and cellular alterations were observed in the aging LA myocardium in SR; however, these alterations were also present in fibrillating and aging atria. As a result of the persistence of pathogenic factors, such as increased pressure load or high frequency of beating, certain myocytes with structural alterations may activate a programmed cell death (PCD) pathway. The results of the present study indicated that aging and/or fibrillating atria contained several myocytes undergoing apoptosis. Myocytes with myolysis may exhibit certain features of dedifferentiation. However, whether the cells undergoing lysis are in a long-term viable state that may be reversed or whether they will die by activating PCD, remains to be determined. In particular, in aging atria, minor additional noxious stimuli, such as high frequency of beating, may be sufficient to trigger the death of occasional vulnerable myocytes in a random manner.

Although calcium signaling is mediated through an array of calcium-dependent enzymes, calpian exhibits the greatest effect on cell function (10). By carrying out selective, limited proteolytic cleavages, calpains modulate the activity of enzymes and induce specific cytoskeletal rearrangements in various aging phenomena and late-life diseases (13). The results of the present study demonstrated that the majority of parameters correlated with one another. The overexpression of the calpain 1 protein was consistent with general cellular alterations, including characteristic reductions in $\mathrm{LVDCC}_{\mathrm{a} 1 \mathrm{c}}$ that resulted in electrical remodeling in the atrial cells and accelerated fibrosis and apoptosis. The data suggested that calpain 1 activation, due to overexpression of calpain 1 in fibrillating and aging atria, may have resulted in gross cellular damage (the structural and molecular changes associated with remodeling). Thus, its activation is likely to contribute to the progress of atrial tissue deterioration. Therefore, intervention in the calpain pathway may be important in determining the sequence of cellular and molecular events in aging and/or AF, and may aid in the identification of a novel strategy for pharmacological intervention.
In conclusion, the results of the present study are limited as the plateau potential of AP is determined by $\mathrm{I}_{\mathrm{Kur}}, \mathrm{I}_{\mathrm{to}}$ and $\mathrm{I}_{\mathrm{Ca}-\mathrm{L}}$; however, $\mathrm{I}_{\mathrm{Kur}}$ and $\mathrm{I}_{\text {to }}$ were not included in this study. Furthermore, APA is related to $\mathrm{I}_{\mathrm{Na}}$, which was not observed in this study. Finally, the results are limited to studies of cells from LA and may not be extended to cells of other regions of the atria. It may have been beneficial to determine the activation of calpain 1 during aging and/or in AF-related atrial structural remodeling; however, calpain 1 requires low (micromolar) intracellular calcium concentrations to be able to reach half-maximum activity, which is expected during AF.

\section{Acknowledgements}

This study was supported by the Program of National Natural Science Foundation of China (grant no. 308660299), the Program of Natural Science Foundation of the Xinjiang Uygur Autonomous Region (grant nos. 200821143 and 2011211A074) and the Program of Doctoral Fund of Ministry of Education (grant no. 200807600004).

\section{References}

1. Nattel S: New ideas about atrial fibrillation 50 years on. Nature 415: 219-226, 2002.

2. Chen LY and Shen WK: Epidemiology of atrial fibrillation: a current perspective. Heart Rhythm 4 (Suppl 3): S1-S6, 2007.

3. Dun W, Yagi T, Rosen MR and Boyden PA: Calcium and potassium currents in cells from adult and aged canine right atria. Cardiovasc Res 58: 526-534, 2003.

4. Anyukhovsky EP, Sosunov EA, Plotnikov A, et al: Cellular electrophysiologic properties of old canine atria provide a substrate for arrhythmogenesis. Cardiovasc Res 54: 462-469, 2002.

5. Anyukhovsky EP, Sosunov EA, Chandra P, et al: Age-associated changes in electrophysiologic remodeling: a potential contributor to initiation of atrial fibrillation. Cardiovasc Res 66: 353-363, 2005

6. Spach MS, Heidlage JF, Dolber PC and Barr RC: Mechanism of origin of conduction disturbances in aging human atrial bundles: experimental and model study. Heart Rhythm 4: 175-185, 2007.

7. Eisner DA, Diaz ME, Li Y, O'Neill SC and Trafford AW: Stability and instability of regulation of intracellular calcium. Exp Physiol 90: 3-12, 2005.

8. Katra RP and Laurita KR: Cellular mechanism of calcium-mediated triggered activity in the heart. Circ Res 96: 535-542, 2005.

9. van Wagoner DR, Pond AL, Lamorgese M, Rossie SS, McCarthy PM and Nerbonne JM: Atrial L-type $\mathrm{Ca}^{2+}$ currents and human atrial fibrillation. Circ Res 85: 428-436, 1999.

10. Croall DE and DeMartino GN: Calcium-activated neutral protease (calpain) system: structure, function, and regulation. Physiol Rev 71: 813-847, 1991.

11. Brundel BJ, Ausma J, van Gelder IC, et al: Activation of proteolysis by calpains and structural changes in human paroxysmal and persistent atrial fibrillation. Cardiovasc Res 54: 380-389, 2002.

12. Daoud EG, Bogun F, Goyal R, et al: Effect of atrial fibrillation on atrial refractoriness in humans. Circulation 94: 1600-1606, 1996.

13. Ausma J, Dispersyn GD, Duimel H, et al: Changes in ultrastructural calcium distribution in goat atria during atrial fibrillation. J Mol Cell Cardiol 32: 355-364, 2000.

14. Allessie M, Ausma J and Schotten U: Electrical, contractile and structural remodeling during atrial fibrillation. Cardiovasc Res 54: 230-246, 2002.

15. Bers DM: Calcium cycling and signaling in cardiac myocytes. Annu Rev Physiol 70: 23-49, 2008.

16. HB Schiefer: Guide to the Care and Use of Experimental Animals, Volume 2. Can Vet J 26: 59, 1985.

17. Yue L, Feng J, Gaspo R, Li GR, Wang Z and Nattel S: Ionic remodeling underlying action potential changes in a canine model of atrial fibrillation. Circ Res 81: 512-525, 1997.

18. Bosch RF and Nattel S. Cellular electrophysiology of atrial fibrillation. Cardiovasc Res 54: 259-269, 2002. 
19. Verheule S, Wilson E, Banthia S, et al: Direction-dependent conduction abnormalities in a canine model of atrial fibrillation due to chronic atrial dilatation. Am J Physiol Heart Circ Physiol 287: H634-H644, 2004.

20. Wijffels MC, Kirchhof CJ, Dorland R and Allessie MA: Atrial fibrillation begets atrial fibrillation. A study in awake chronically instrumented goats. Circulation 92: 1954-1968, 1995.

21. Willems R, Holemans P, Ector H, Sipido KR, Van de Werf F and Heidbüchel $\mathrm{H}$ : Mind the model: effect of instrumentation on inducibility of atrial fibrillation in a sheep model. J Cardiovasc Electrophysiol 13: 62-67, 2002.

22. Nattel S, Khairy P and Schram G: Arrhythmogenic ionic remodelling: adaptive responses with maladaptive consequences. Trends Cardiovasc Med 11: 295-301, 2001.

23. Baba S, Dun W, Hirose M and Boyden PA: Sodium current function in adult and aged canine atrial cells. Am J Physiol Heart Circ Physiol 291: H756-H761, 2006.

24. Tanaka K, Zlochiver S, Vikstrom KL, et al: Spatial distribution of fibrosis governs fibrillation wave dynamics in the posterior left atrium during heart failure. Circ Res 101: 839-847, 2007.

25. Wit AL and Boyden PA: Triggered activity and atrial fibrillation. Heart Rhythm 4 (Suppl 3): S17-S23, 2007.

26. Weiss JN, Qu Z, Chen PS, et al: The dynamics of cardiac fibrillation. Circulation 112: 1232-1240, 2005.
27. Everett TH IV and Olgin JE: Atrial fibrosis and the mechanisms of atrial fibrillation. Heart Rhythm 4 (Suppl 3): S24-S27, 2007.

28. Qu Z, Garfinkel A, Chen PS and Weiss JN: Mechanisms of discordant alternans and induction of reentry in simulated cardiac tissue. Circulation 102: 1664-1670, 2000.

29. Miragoli M, Gaudesius G and Rohr S: Electrotonic modulation of cardiac impulse conduction by myofibroblasts. Circ Res 98: 801-810, 2006.

30. Koura T, Hara M, Takeuchi S, et al: Anisotropic conduction properties in canine atria analyzed by high-resolution optical mapping: preferential direction of conduction block changes from longitudinal to transverse with increasing age. Circulation 105: 2092-2098, 2002.

31. Thijssen VL, Ausma J, Liu GS, Allessie MA, van Eys GJ and Borgers M: Structural changes of atrial myocardium during chronic atrial fibrillation. Cardiovasc Pathol 9: 17-28, 2000.

32. Mandapati R, Skanes A, Chen J, Berenfeld O and Jalife J: Stable microreentrant sources as a mechanism of atrial fibrillation in the isolated sheep heart. Circulation 101: 194-199, 2000.

33. Ausma J, Wijffels M, Thoné F, Wouters L, Allessie M and Borgers M: Structural changes of atrial myocardium due to sustained atrial fibrillation in the goat. Circulation 96: 3157-3163, 1997. 